\title{
Investigation on susceptible variants to arrhythmia in forensic autopsy cases of SCDs caused by cardiomyopathy: assessment with the candidate SNPs
}

\author{
Mei-Hui Tian \\ China Medical University \\ Yu-Qing Jia \\ China Medical University \\ Mao-Mao Zhao \\ China Medical University \\ Zhi-Xin Huo \\ China Medical University \\ Si-Yi Zhang \\ China Medical University \\ Xiao-Ni Zhan \\ China Medical University \\ Xin-Rui Yang \\ China Medical University \\ Bao-Li Zhu \\ China Medical University \\ Hao Pang ( $\square$ hpang@cmu.edu.cn ) \\ China Medical University https://orcid.org/0000-0002-6606-6438
}

Research article

Keywords: SCD, Cardiomyopathy, Arrhythmia, ARVC, SNP, Forensic

Posted Date: August 9th, 2019

DOI: https://doi.org/10.21203/rs.2.12565/v1

License: (c) (i) This work is licensed under a Creative Commons Attribution 4.0 International License. Read Full License 


\section{Abstract}

Background: Fatal arrhythmia is a common cause of sudden cardiac death (SCD) in patients with cardiomyopathies. Nowadays, associations of many genetic variants with cardiomyopathy have gradually been highlighted, however, whether the arrhythmia-related single nucleotide polymorphisms (SNPs) are associated with SCDs caused by cardiomyopathies is elusive. To identify the genetic susceptible factors in cardiomyopathy, a retrospective study was conducted from the autopsy cases. Methods: The present study was composed of 223 forensic autopsy cases including 51 SCDs caused by cardiomyopathies and 172 controls. The cardiomyopathy cases were made up of arrhythmogenic right ventricular cardiomyopathy (ARVC, $\mathrm{n}=27)$ and NonARVC [ $\mathrm{n}=24$, including hypertrophic cardiomyopathy, dilated cardiomyopathy, restrictive cardiomyopathy, and unclassified cardiomyopathy]. Four arrhythmiarelated candidate SNPs: rs4687718, rs7366407, rs4292933, and rs2824292) were genotyped by polymerase chain reaction-restriction fragment length polymorphism (PCR-RFLP) method. Association between genotypes and the risk of SCD was assessed by stratification of the cardiomyopathy (ARVC cases vs. Non-ARVC cases). Results: The A-allele and dominant model (AA + AG vs. GG) of rs4687718 on transketolase gene (TKT) were significantly associated with cardiomyopathies (ORA allele $=2.481,95 \%$ CIA allele: $1.262-4.876$, PA allele $=0.007$; ORAA+AG genotype $=2.580,95 \%$ CIAA+AG genotype: $1.206-5.519$, $\mathrm{PAA}+\mathrm{AG}$ genotype value $=0.012$ ). After stratification by cardiomyopathy subtypes, the allelic and genotypic frequencies of rs 4687718 in Non-ARVC group were significantly different compared to controls, and between ARVC group and controls the difference was only duplicated in genotypic frequency. In the light of analyses of the different genetic models, however, there were no significant differences between Non-ARVC group and controls, but the AA + AG vs. GG model was associated with ARVC group. No significant differences were detected for other three SNPs. Conclusion: Our results revealed an association between TKT rs4687718 and SCDs caused by cardiomyopathy in Chinese autopsy cases. These findings highlighted the important role of molecular testing and may play in propensity toward in clinical prediction and forensic identification of cardiomyopathy SCDs. It also provided the basis for the classification of different types of cardiomyopathy at the genetic level.

\section{Background}

Sudden cardiac death (SCD) is a sudden, unexpected death caused by loss of cardiac function [1]. In China, the incidence of SCD is $41.8 / 100,000$, while the total number is estimated as 544,000 per year [2]. Two-third of the SCD cases have been reported to have structural abnormalities of the heart, and cardiomyopathy was the one of the major components $[3,4]$. Cardiomyopathy is defined as a myocardial disorder in which the heart muscle is structurally and functionally abnormal, in the absence of coronary artery disease, hypertension, valvular disease and congenital heart disease sufficient to cause the observed myocardial abnormality [5]. It can be classified as hypertrophic cardiomyopathy (HCM), dilated cardiomyopathy (DCM), arrhythmogenic right ventricular cardiomyopathy (ARVC), restrictive cardiomyopathy (RCM), and nonclassifiable cardiomyopathy [6].

Heart failure (HF) is the direct cause of death for cardiomyopathy in clinical, while in the practice of forensic medicine, fatal arrhythmia is the first to be responsible for the SCD $[7,8]$. Because of the different classifications, the mechanisms of SCD in cardiomyopathies are not the same, but three theories including abnormal energy metabolism of cardiomyocytes, dysfunction of ion channels and viral infection are widely accepted [9-11]. As the highlighting of genetic contribution to cardiomyopathy, thousands to millions of candidate single nucleotide polymorphisms (SNPs) in genome-wide association studies (GWAS) have been reported to be associated with cardiomyopathy SCDs, in genes encoding several categories of proteins, including those of sarcomeres, desmosomes, cytoskeleton, and nuclear envelope [12,13]. These results not only contribute to the clinical diagnosis and treatment of cardiomyopathy, and also expect to make some breakthrough in the current status of forensic cardiomyopathy identification, which mainly based on the different pathological features under the premise of excluding other causes of death [14]. Although many facts have suggested that there must have some consequent relationship between cardiomyopathy and arrhythmias, arrhythmia-related variants have never been explored in patients with cardiomyopathy. Therefore, we chose candidate SNPs of four genes based on the mechanism of sudden death of cardiomyopathy, and conducted a systematic genetic association investigation in case-control study of SCD with cardiomyopathy.

\section{Methods}

\section{Subjects and sample collection}

The study protocol was approved by the ethics committee of China Medical University (no. [2017]062). A total of 223 forensic autopsy cases from Department of Forensic Pathology, School of Forensic Medicine of China Medical University were enrolled, including 51 SCD cases caused by cardiomyopathies and 172 controls. The cardiomyopathy cases were made up of ARVC $(n=27)$ and Non-ARVC $[n=24$, including HCM $(n=13), \operatorname{DCM}(n=5), \operatorname{RCM}(n=2)$, and unclassified cardiomyopathy $(n=4)$ ] in this study. The causes of death were determined on the basis of a comprehensive medico-legal investigation, including autopsy examination and histological, toxicological and biochemical analyses.

Worldwide, pathological features of heart are the most important and primary basis for forensic identification and classification of cardiomyopathies, and related literatures can also provide complementary supports. The key points of different types of cardiomyopathies used commonly in China are as follows: ARVC [15], according to Protonotarios and Basso's diagnostic criteria, severely dilated right ventricle involving advanced myocardial atrophy with fibrofatty replacement in the right ventricular free wall, and not accompanied by lesion of conducting system and coronary arteries; $\mathrm{HCM}$, a) increased thickness of inter ventricular septum and left ventricular wall, the ratio of interventricular septum to left ventricular wall is more than 1.3. b) increased weight of heart, often exceeds 500 g. c) incrassated endocardium and white plaque forms; DCM, increased heart volume, weight, and four chambers of the heart, ventricular cavity to expand more apparent; RCM, thickened left ventricular posterior wall and interventricular septum, decreased ventricular cavity, and increased subendocardial myocardial interstitial fibrous tissue; unclassified cardiomyopathy, arrhythmias and cardiac conduction disorders were the main manifestations. For the control group, 172 victims with non-related cardiac causes of death, including traffic accidents and high falls, were selected. All of the control victims were without any known cardiovascular disease, according to the anatomical and pathological findings, postmortem biochemical detection results (including NT-pro brain natriuretic peptide, troponin T, troponin I, and creatine kinase-MB), and clinical records (if provided). 
The basic conditions of gender, age, and heart weight of the cardiomyopathy and control groups were well documented. The results were blind evaluated by three pathologists. Samples of 35 cases with cardiomyopathy were obtained from formalin-fixed paraffin-embedded (FFPE) tissue, and those of the remaining 16 cases with cardiomyopathy and all controls were obtained from body fluids, including freeze-thaw blood, urine and pericardial fluid.

\section{Genomic DNA isolation and genotyping}

The genomic DNA was extracted by the sodium dodecyl sulfate-protease K-phenol-chloroform method. The freeze-thaw blood and FFPE samples were pretreated before DNA extraction. In brief, for freeze-thaw blood, centrifugated (10000 rpm, $10 \mathrm{~min}$ ) to collect the underlying sediments. While as for FFPE samples, $20 \mu \mathrm{m}$ thick sections of FFPE tissue blocks were collected into sterile microtubes. Removed the paraffin by adding $1 \mathrm{~mL}$ xylene in $56^{\circ} \mathrm{C}$ for 30 min followed by vortex and centrifugation (10000 rpm, $10 \mathrm{~min}$ ), the supernatant was removed with a sterile transfer pipette. This step was repeated. After removing the xylene, the samples were washed twice with pure ethanol, and air dried.

The primers and restriction endonucleases used for polymerase chain reaction-restriction fragment length polymorphism (PCR-RFLP) were based on the published sequences in GenBank. Considering that there were some FFPE tissue samples have been stored for several years, combined with the results of the preliminary experiments, the length of all amplified products were controlled within $140 \mathrm{bp}$. The primers used for SNPs detection, restriction endonucleases used for genotyping and amplified products are shown in Table 1.

PCR-RFLP technique was used to identify the SNPs. PCR was conducted in a final volume of $20 \mu \mathrm{L}$ PCR buffer containing $2 \mu \mathrm{L}$ genomic DNA (approximately 20 - $50 \mathrm{ng} / \mu \mathrm{L}), 10 \mu \mathrm{L} 2 \times$ PowerTaq PCR StarMix with Loading Dye (GenStar, Beijing, China), $0.5 \mu \mathrm{L}$ forward and reverse primers and $7 \mu \mathrm{L}$ dd $\mathrm{H}_{2} \mathrm{O}$. PCR was carried out on a PCR Thermal Cycler Dice (Takara, Japan) with initial denaturation at $94^{\circ} \mathrm{C}$ for 1 min, followed by 35 cycles of denaturing for $15 \mathrm{~s}$ at $94^{\circ} \mathrm{C}$, annealing for $30 \mathrm{~s}\left(55^{\circ} \mathrm{C}\right.$ for rs 4687718 and rs $4292933 ; 60^{\circ} \mathrm{C}$ for rs7366407 and rs2824292), extension at $72^{\circ} \mathrm{C}$ for $20 \mathrm{~s}$; and final extension at $72^{\circ} \mathrm{C}$ for $1 \mathrm{~min}$. For restriction enzyme digestion, $1 \mu \mathrm{L}$ PCR product and $0.25 \mu \mathrm{L}$ restriction endonuclease (Takara, Dalian, China) were mixed in $10 \mu \mathrm{L}$ corresponding buffer. PCR products were incubated at $37^{\circ} \mathrm{C}$ for more than $1 \mathrm{~h}$ and the digestion products were separated by $10 \%$ polyacrylamide gel electrophoresis. Fragments were visualized by the Molecular Imager Gel DocXR+System (Bio-Rad, Hercules, CA, USA) after ethidium bromide staining.

\section{Statistical analysis}

The Hardy-Weinberg equilibrium (HWE) test for frequency distribution was calculated using PowerMarker version 3.0. Results were analysed using the SPSS version 19.0 software. The differences among groups were assessed using one-way analysis of variance (ANOVA) and Chi-square/Fisher's exact tests. A twotailed $P$-value $\leq 0.05$ was considered significant. Odds ratios (ORs), with their corresponding $95 \%$ confidence intervals (Cls), were used to evaluate the strength of the association between the polymorphisms and cardiomyopathy risk.

\section{Results}

\section{Case profiles}

The demographics and heart weights of each group were shown in Table 2. Gender compositions and age distributions between the cardiomyopathies and controls did not show statistically significant differences $\left(P_{\text {gender }}=0.539 ; P_{\text {age }}=0.304\right)$. The weights of hearts in cardiomyopathy group were heavier than the controls $(P<0.001)$. It is worth to be explained that in the control group, a small number of decedents had a more than $500 \mathrm{~g}$ heart, however, they were not diagnosed as cardiomyopathy after pathological anatomy and biochemical examination, and therefore those were not eliminated in this study.

\section{Genotyping the four SNPs}

The mismatched PCR amplifications were first performed, and sequences containing the Hind III, Nco I and Afa I recognition sites were confirmed by DNA sequencing. Subsequently, genotypes in the four loci were examined by PCR-RFLP method in all samples. The results showed that the mismatched PCR-RFLP assays were successful and genotypes in the four SNPs were determined in all investigated samples.

\section{Genetic association of four SNPs with cardiomyopathy}

The distributions of genotypic and allelic frequencies of four SNPs in cardiomyopathy cases and controls are summarized in Table 3. The actual HWE $P$ values of rs4687718, rs7366407, rs4292933, and rs2824292 in control group was $0.172,0.649,0.724$, and 0.661 , respectively. The genotypic and allelic frequencies of rs 4687718 were significantly different between cardiomyopathy cases and controls $\left(P_{\text {genotype }}=0.038 ; \mathrm{OR}_{\mathrm{A} \text { allele }}=2.481,95 \% \mathrm{Cl}_{\mathrm{A} \text { allele: }} 1.262\right.$ $\left.4.876, P_{\text {A allele }}=0.007\right)$. Association analyses of rs7366407, rs4292933, and rs2824292 showed that there were no significant differences between cardiomyopathy cases and controls. The difference in genotypes of rs 4687718 locus between cardiomyopathy cases and controls was significant in the dominant model of AA + AG vs. GG $(\mathrm{OR}=2.580,95 \% \mathrm{Cl}: 1.206-5.519, P=0.012)$, but not in the other three models $(P$ values: $0.186,0.634$, and 0.225 , respectively) (Table 4).

\section{Genetic association of four SNPs by stratification of the cardiomyopathy}

We analyzed the ARVC case as a specific type of cardiomyopathy, and the other four types of cardiomyopathies (including HCM, DCM, RCM and unclassified cardiomyopathy) were collectively referred to Non-ARVC group. There were no significant difference in genotypic and allelic frequencies of four SNPs between ARVC cases and Non-ARVC cases. In order to figure out the source of differences between the cardiomyopathy group and the controls, we also compared ARVC and Non-ARVC cases to the controls, respectively. After stratification, the genotypic and allelic frequencies of rs 4687718 were significant different between the Non-ARVC cases and controls $\left(P_{\text {genotype }}=0.047 ; \mathrm{OR}_{\mathrm{A} \text { allele }}=2.667,95 \% \mathrm{Cl}_{\mathrm{A} \text { allele }}: 1.123-6.334, P_{\mathrm{A} \text { allele }}=0.044\right)$. The genotypic frequency of 
rs4687718 was significant different between ARVC cases and controls $\left(P_{\text {genotype }}=0.039\right)$, but not in allelic frequency. When analyzed by different genetic models, the compared data between the two groups were quite impressive. The results showed that the dominant model (AA + AG vs. GG) was significant associated with ARVC cases ( $\mathrm{OR}=2.871,95 \% \mathrm{Cl}$ : $1.222-7.345, P=0.047)$, while no differences were confirmed in all four models in Non-ARVC group. Association analyses of rs7366407, rs4292933, and rs2824292 showed that there were no significant differences in genotypes and alleles between ARVC cases and controls, as well as Non-ARVCs and controls.

\section{Discussion}

Based on the relationship between arrhythmias and SCD, several arrhythmia-related mutations in multiple genes have been identified in a variety of cardiovascular diseases, including coronary heart disease, cardiac channelopathies, and sudden unexplained nocturnal death syndrome [11, 16-18]. In the current study, we selected four SNPs, which have been proved associated with arrhythmias under GWAS's profile, to evaluate their role as predisposing factors for cardiomyopathy SCDs in forensic autopsy cases. An association between the rs4687718 on transketolase gene (TKT) and cardiomyopathy SCDs was found. However, our results didn't show significant differences in the genotypic and allelic frequencies of rs7366407, rs4292933, and rs2824292 between the cardiomyopathy cases and controls.

Transketolase is a reversible, thiamine-dependent enzyme in the pentose phosphate pathway, and associated with energy metabolism and the regulation of cardiac contraction $[19,20]$. Mutations in TKT could cause a syndrome which performance forcongenital heart defects, short stature, and developmental delay [21]. Researchers have also shown that rs 4687718 located on the intron 5 of TKT was associated with QRS interval of ECG, and could increase the risk of SCD in European-ancestry populations [22]. In our study, the results for the rs 4687718 showed statistically significant difference between cardiomyopathy cases and controls, revealing the potential relationship between arrhythmias and cardiomyopathies. The results for the genetic model demonstrated that the A-allele of rs 4687718 and dominant models (AA + AG vs. GG) played a strong risk role in cardiomyopathies in northern Chinese population. Interestingly, genetic studies of rs 4687718 on the TKT with cardiac function are usually conducted in conjunction with calcium voltage-gated channel subunit alpha 1D gene (CACNA1D) [22]. CACNA1D encode the a1 subunits of cardiac L-type calcium channels (LTCCs), and many mutations found in CACNA1D were associated with ventricular arrhythmias [23]. It was observed that markers located at a physical distance of less than $10 \mathrm{Mb}$ on the same chromosome were easily LD. The linkage location implies that rs4687718 on TKT is a mirror of some unknown associated SNPs on CACNA1D, which may form functional haplotype and merits further evaluation.

Numerous investigations have shown that ions in the myocardium, especially calcium $\left(\mathrm{Ca}^{2+}\right)$ ions, are closely related to the occurrence of arrhythmias [17, 24]. Given the expanding body of literature linking alterations in $\mathrm{Ca}^{2+}$-handling with myocardial remodeling, investigators have begun to explore whether mutations in genes encoding $\mathrm{Ca}^{2+}$-handling proteins might be associated with cardiomyopathies [25]. Calsequestrin 2 gene (CASQ2) encodes the intra-sarcoplasmic reticulum $\mathrm{Ca}^{2+}$ binding protein cardiac calsequestrin, and nitric oxide synthase 1 adaptor protein gene (NOS1AP) is also involved in LTCCs by encoding a cytosolic protein that binds to the neuronal nitric oxide synthase (nNOS) [26]. It has been demonstrated by independent groups and in different populations that allelic variants in CASQ2 were associated with ventricular tachycardia, HF and SCD [27-29]. Mutations of the NOS1AP are strongly associated with abnormalities of the QT interval of the ECG, and some SNPs on the gene are also associated with the risk of SCD [26, 30-33]. Researchers have found the rs7366407 near CASQ2 and rs4292933 in NOS1AP were associated with SCD in European, however it has not been verified in Chinese cardiomyopathy patients $[26,34,35]$. Though these two SNPs did not result in a statistically significant association with cardiomyopathy in the present study, it was also the first to investigate the polymorphism's influence on cardiomyopathy patients from the Chinese mainland.

A recent GWAS for SCD in the arrhythmia genetics in the Netherlands population has led to the attention of a SNP rs 2824292 might be in arrhythmia susceptibility [36]. The rs2824292 locates on the vicinity of the CXADR gene in chromosome 21q21, and it is in complete LD with rs2824293 [37]. CXADR encodes the coxsackie and adenovirus receptor (CAR), which plays a role in the electrical conduction of the heart [38, 39]. Although the present result didn't show significant difference between cardiomyopathy cases and controls, considering the arrhythmia susceptibility in chromosome 21q21, this CXADR still deserves further study [36].

To better explore the association between arrhythmias and cardiomyopathy SCD, we set ARVC as an independent subgroup. ARVC is a familial cardiac disease characterized by ventricular arrhythmias and SCD, and it is the most common cause of SCD in young people [40]. As the sudden death is often the first symptom of this disease, it is urgent to explore the cause and mechanism of the disease in clinic. On the other hand, patients who die of ARVC usually only show nonspecific myocardial atrophy with fibrofatty replacement in the right ventricular in autopsy. Thus, SNPs in the candidate genes is likely to be an auxiliary indicator for both clinical diagnosis and forensic identification. Until now, associations of many genes with ARVC have been demonstrated, in which the structural proteins of desmosome occupied a significantly higher proportion [41]. However, to our knowledge, there were few reports on the association of arrhythmia-related mutations with ARVC, particularly in these four genes of autopsy cases. Our results showed that the A-allele of rs4687718 was significantly associated with Non-ARVC cases but not with ARVC cases. Besides, compared to controls, although rs4687718 on TKT showed different genotype frequencies in both ARVC and Non-ARVC cases, but the dominant model (AA + AG vs. GG) was significant associated with ARVC, while not with Non-ARVC. The results from the genetic models by stratification suggested that the dominant model plays a major role in the differences of genotypes in ARVC cases. It provided some evidences for the genetic testing as a potential method to both clinical prevention and forensic identification of SCD caused by ARVC. Furthermore, the differences in allelic and genotypic frequencies between ARVC and controls as well as Non-ARVC and controls also suggested that investigation on more susceptible genes in more samples may be helpful for identify different types of cardiomyopathy at the genetic level.

In summary, some genetic variants associated with arrhythmias may be also associated with cardiomyopathy SCDs. These findings highlight the important role of molecular testing and may play in propensity toward in clinical prevention and forensic identification of cardiomyopathy. To clinical, associations between particular SNPs and the SCDs caused by cardiomyopathy provide us unparalleled opportunities to find key susceptible and pathogenic genes, which can also improve the prediction of risk of adverse events in patients. On the other hand, the discovery of high-risk SNPs provides a new direction for forensic 
identification of SCDs caused by cardiomyopathy, especially by ARVC. Therefore, if these findings are replicated in other populations, variants in these genes may provide more evidences for forensic identification and clinical prediction of SCDs with cardiomyopathies.

The size of the cardiomyopathy cases in the present study was a considerable limitation. As we all know, the inclusion of more samples makes more meaningful for genetic analysis. In consideration of this point, we prudently enrolled all cases of SCD with cardiomyopathy from our previous autopsies and screened at the same time control samples from the cases without cardiomyopathy as many as possible, to increase the cogency of the data. It is valuable that further studies of cardiomyopathy will be conducted in larger samples.

\section{Conclusions}

Overall, this is the first to investigate the association between cardiomyopathy SCDs and arrhythmia- related mutations in Chinese autopsy cases. These finding revealed that rs4687718 on TKT may be associated with cardiomyopathy. The detection of genes might be a new indicator for the forensic identification of cardiomyopathy. Further study in other cardiomyopathy-associated SNPs and in other populations may obtain more important insights into the identification to cardiomyopathy in forensic expertise.

\section{Abbreviations}

AIC: Arrhythmia-induced cardiomyopathy; ANOVA: One-way analysis of variance; ARVC: Arrhythmogenic right ventricular cardiomyopathy; CACNA1D: Calcium voltage-gated channel subunit alpha 1D gene; CAR: Coxsackie and adenovirus receptor; CASQ2: Calsequestrin 2 gene; Cls: Confidence intervals; DCM: Dilated cardiomyopathy; FFPE: Formalin-fixed paraffin-embedded; GWAS: Genome-wide association studies; HCM: Hypertrophic cardiomyopathy; HF: Heart failure; HWE: Hardy-Weinberg equilibrium; LD: linkage disequilibrium; LTCCs: L-type calcium channels; nNOS: Neuronal nitric oxide synthase; NOS1AP: Nitric oxide synthase 1 adaptor protein gene; OR: Odds ratio; PCR-RFLP: Polymerase chain reaction-restriction fragment length polymorphism; RCM: Restrictive cardiomyopathy; SCD: Sudden cardiac death; TKT: Transketolase gene.

\section{Declarations}

\section{Ethics approval and consent to participate}

All procedures performed in studies involving human participants were in accordance with the ethical standards of the institutional and/or national research committee and with the 1964 Helsinki declaration and its later amendments or comparable ethical standards.

\section{Consent for publication}

Not applicable

\section{Availability of data and materials}

The dataset analyzed during the current study are available from the corresponding author on reasonable request.

\section{Competing interests}

The authors declare that they have no conflict of interest.

\section{Funding}

This study was supported by the initial funding from China Medical University.

\section{Authors' contributions}

MHT\&HP set up the study design and interpreted the data. MHT, MMZ, ZXH, YQJ \&HP performed the statistical analyses, interpreted the data and drafted the manuscript. BLZ, HP\&YQJ revised the manuscript critically and provided continuous guidance throughout the study. MHT, YQJ,SYZ, XNZ \&XRY collecting the data and do the experiments. All authors read and approved the final manuscript.

\section{Acknowledgments}

We would like to thank all the participants in our study.

\section{References}

1. Adamczak DM, Oko-Sarnowska Z. Sudden cardiac death in hypertrophic cardiomyopathy. Cardiol Rev. 2018; 26(3):145-151.

2. Wang H, Yao Q, Zhu S, Zhang G, Wang Z, Li Z, Sun R, Lu C, Li C, Pu J. The autopsy study of 553 cases of sudden cardiac death in Chinese adults. Heart Vessels. 2014; 29(4):486-495.

3. Hertz CL, Ferrero-Miliani L, Frank-Hansen R, Morling N, Bundgaard H. A comparison of genetic findings in sudden cardiac death victims and cardiac patients: the importance of phenotypic classification. Europace. 2015; 17(3):350-357. 
4. Arking DE, Junttila MJ, Goyette P, Huertas-Vazquez A, Eijgelsheim M, Blom MT, Newton-Cheh C, Reinier K, Teodorescu C, Uy-Evanado A et al. Identification of a sudden cardiac death susceptibility locus at 2q24.2 through genome-wide association in European ancestry individuals. Plos Genet. 2011; 7(6):e1002158.

5. Elliott P, Andersson B, Arbustini E, Bilinska Z, Cecchi F, Charron P, Dubourg O, Kuhl U, Maisch B, McKenna WJ et al. Classification of the cardiomyopathies: a position statement from the European society of cardiology working group on myocardial and pericardial diseases. Eur Heart J. 2008; 29(2):270-276.

6. McKenna WJ, Maron BJ, Thiene G. Classification, epidemiology, and global burden of cardiomyopathies. Circ Res. 2017; 121(7):722-730.

7. Crotti L, Kotta MC. The role of genetics in primary ventricular fibrillation, inherited channelopathies and cardiomyopathies. Int J Cardiol. 2017; $237: 45-48$.

8. Songsirisuk N, Kittipibul V, Methachittiphan N, Charoenattasil V, Zungsontiporn N, Spanuchart I, Buppajarntham S, Mankongpaisarnrung C, Satitthummanid S, Srimahachota S et al. Modes of death and clinical outcomes in adult patients with hypertrophic cardiomyopathy in Thailand. BMC Cardiovasc Disord. 2019; 19(1):1.

9. Baksi AJ, Kanaganayagam GS, Prasad SK. Arrhythmias in viral myocarditis and pericarditis. Card Electrophysiol Clin. 2015; 7(2):269-281.

10. Dass S, Cochlin LE, Suttie JJ, Holloway CJ, Rider OJ, Carden L, Tyler DJ, Karamitsos TD, Clarke K, Neubauer S et al. Exacerbation of cardiac energetic impairment during exercise in hypertrophic cardiomyopathy: a potential mechanism for diastolic dysfunction. Eur Heart J. 2015; 36(24):1547-1554.

11. Bers DM, Chen-Izu Y. Sodium and calcium regulation in cardiac myocytes: from molecules to heart failure and arrhythmia. J Physiol. 2015; 593(6):13271329.

12. Bezzina CR, Lahrouchi N, Priori SG. Genetics of sudden cardiac death. Circ Res. 2015; 116(12):1919-1936.

13. Magi S, Lariccia V, Maiolino M, Amoroso S, Gratteri S. Sudden cardiac death: focus on the genetics of channelopathies and cardiomyopathies. J Biomed Sci. 2017; 24(1):56.

14. Balla C, Vitali F, Brieda A, Gualandi F, Ferlini A, Bertini M, Ferrari R. Predictors of cardiac arrhythmic events in non coronary artery disease patients. BMC Cardiovasc Disord. 2019; 19(1):104.

15. Cao ZP, Xue JJ, Zhang Y, Tian MH, Xiao Y, Jia YQ, Zhu BL. Differential expression of B-type natriuretic peptide between left and right ventricles, with particular regard to sudden cardiac death. Mol Med Rep. 2017; 16(4):4763-4769.

16. Osadchii OE. Role of abnormal repolarization in the mechanism of cardiac arrhythmia. Acta Physiol (Oxf). $2017 ; 220$ Suppl 712:1-71.

17. Albert CM, MacRae CA, Chasman DI, VanDenburgh M, Buring JE, Manson JE, Cook NR, Newton-Cheh C. Common variants in cardiac ion channel genes are associated with sudden cardiac death. Circ Arrhythm Electrophysiol. 2010; 3(3):222-229.

18. Huang L, Yu Y, Chen Y, Tester DJ, Tang S, Ackerman MJ, Yuan Z, Cheng J. Association of common variants in NOS1AP gene with sudden unexplained nocturnal death syndrome in the southern Chinese Han population. Int J Legal Med. 2014; 128(6):933-938.

19. Zhao J, Zhong CJ. A review on research progress of transketolase. Neurosci Bull. 2009; 25(2):94-99.

20. Yang W, Wei X, Su X, Shen Y, Jin W, Fang Y. Depletion of beta3-adrenergic receptor induces left ventricular diastolic dysfunction via potential regulation of energy metabolism and cardiac contraction. Gene. 2019.

21. Boyle L, Wamelink M, Salomons GS, Roos B, Pop A, Dauber A, Hwa V, Andrew M, Douglas J, Feingold M et al. Mutations in TKT are the cause of a syndrome including short stature, developmental delay, and congenital heart defects. Am J Hum Genet. 2016; 98(6):1235-1242.

22. Sotoodehnia N, Isaacs A, de Bakker PI, Dorr M, Newton-Cheh C, Nolte IM, van der Harst P, Muller M, Eijgelsheim M, Alonso A et al. Common variants in 22 loci are associated with QRS duration and cardiac ventricular conduction. Nat Genet. 2010; 42(12):1068-1076.

23. Rangaraju A, Krishnan S, Aparna G, Sankaran S, Mannan AU, Rao BH. Genetic variants in post myocardial infarction patients presenting with electrical storm of unstable ventricular tachycardia. Indian Pacing Electrophysiol J. 2018; 18(3):91-94.

24. Landstrom AP, Dobrev D, Wehrens X. Calcium signaling and cardiac arrhythmias. Circ Res. 2017; 120(12):1969-1993.

25. Landstrom AP, Ackerman MJ. Beyond the cardiac myofilament: hypertrophic cardiomyopathy- associated mutations in genes that encode calciumhandling proteins. Curr Mol Med. 2012; 12(5):507-518.

26. Westaway SK, Reinier K, Huertas-Vazquez A, Evanado A, Teodorescu C, Navarro J, Sinner MF, Gunson K, Jui J, Spooner P et al. Common variants in CASQ2, GPD1L, and NOS1AP are significantly associated with risk of sudden death in patients with coronary artery disease. Circ Cardiovasc Genet. 2011; 4(4):397-402.

27. Refaat MM, Aouizerat BE, Pullinger CR, Malloy M, Kane J, Tseng ZH. Association of CASQ2 polymorphisms with sudden cardiac arrest and heart failure in patients with coronary artery disease. Heart Rhythm. 2014; 11(4):646-652.

28. Josephs K, Patel K, Janson CM, Montagna C, McDonald TV. Compound heterozygous CASQ2 mutations and long-term course of catecholaminergic polymorphic ventricular tachycardia. Mol Genet Genomic Med. 2017; 5(6):788-794.

29. Rajagopalan A, Pollanen MS. Sudden death during struggle in the setting of heterozygosity for a mutation in calsequesterin 2. Forensic Sci Med Pathol. 2016; 12(1):86-89.

30. Earle N, Yeo HD, Pilbrow A, Crawford J, Smith W, Shelling AN, Cameron V, Love DR, Skinner JR. Single nucleotide polymorphisms in arrhythmia genes modify the risk of cardiac events and sudden death in long QT syndrome. Heart Rhythm. 2014; 11(1):76-82.

31. Earle N, Ingles J, Bagnall RD, Gray B, Crawford J, Smith W, Shelling AN, Love DR, Semsarian C, Skinner JR. NOS1AP polymorphisms modify QTc interval duration but not cardiac arrest risk inhypertrophic cardiomyopathy. J Cardiovasc Electrophysiol. 2015; 26(12):1346-1351.

32. Zhang R, Chen F, Yu H, Gao L, Yin X, Dong Y, Yang Y, Xia Y. The genetic variation rs12143842 in NOS1AP increases idiopathic ventricular tachycardia risk in Chinese Han populations. Sci Rep. 2017; 7(1):8356. 
33. Crotti L, Monti MC, Insolia R, Peljto A, Goosen A, Brink PA, Greenberg DA, Schwartz PJ, George AJ. NOS1AP is a genetic modifier of the long-QT syndrome. Circulation. 2009; 120(17):1657-1663.

34. Aouizerat BE, Vittinghoff E, Musone SL, Pawlikowska L, Kwok PY, Olgin JE, Tseng ZH. GWAS for discovery and replication of genetic loci associated with sudden cardiac arrest in patients with coronary artery disease. BMC Cardiovasc Disord. 2011; 11:29.

35. Liu Z, Liu X, Yu H, Pei J, Zhang Y, Gong J, Pu J. Common variants in TRDN and CALM1 are associated with risk of sudden cardiac death in chronic heart failure patients in Chinese han population. Plos One. 2015; 10(7):e132459.

36. Bezzina CR, Pazoki R, Bardai A, Marsman RF, de Jong J, Blom MT, Scicluna BP, Jukema JW, Bindraban NR, Lichtner P et al. Genome-wide association study identifies a susceptibility locus at 21q21 for ventricular fibrillation in acute myocardial infarction. Nat Genet. 2010; 42(8):688-691.

37. Marsman RF, Wilde AA, Bezzina CR. Genetic predisposition for sudden cardiac death in myocardial ischaemia: the arrhythmia genetics in the Netherlands study. Neth Heart J. 2011; 19(2):96-100.

38. Marsman RF, Bezzina CR, Freiberg F, Verkerk AO, Adriaens ME, Podliesna S, Chen C, Purfurst B, Spallek B, Koopmann TT et al. Coxsackie and adenovirus receptor is a modifier of cardiac conduction and arrhythmia vulnerability in the setting of myocardial ischemia. J Am Coll Cardiol. 2014; 63(6):549-559.

39. Shetty PB, Tang H, Tayo BO, Morrison AC, Hanis CL, Rao DC, Young JH, Fox ER, Boerwinkle E, Cooper RS et al. Variants in CXADR and F2RL1 are associated with blood pressure and obesity in African-Americans in regions identified through admixture mapping. J Hypertens. 2012; 30(10):1970-1976.

40. Bennett RG, Haqqani HM, Berruezo A, Della BP, Marchlinski FE, Hsu CJ, Kumar S. Arrhythmogenic cardiomyopathy in 2018-2019: ARVC/ALVC or both? Heart Lung Circ. 2019; 28(1):164-177.

41. Gandjbakhch E, Redheuil A, Pousset F, Charron P, Frank R. Clinical diagnosis, imaging, and genetics of arrhythmogenic right ventricular cardiomyopathy/dysplasia: JACC state-of-the-art review. J Am Coll Cardiol. 2018; 72(7):784-804.

\section{Tables}

\begin{tabular}{|c|c|c|c|c|c|c|}
\hline SNP & Gene & $\begin{array}{l}\text { Nucleotide } \\
\text { changes }\end{array}$ & $\begin{array}{l}\text { Primer } \\
\text { direction }\end{array}$ & Sequence $\left(5^{\prime} \rightarrow 3^{\prime}\right)$ & $\begin{array}{l}\text { Fragment size } \\
\text { (no. bp) }\end{array}$ & $\begin{array}{l}\text { Restriction } \\
\text { endonuclease }\end{array}$ \\
\hline \multirow[t]{2}{*}{ rs4687718 } & TKT & $\mathrm{G}>\mathrm{A}$ & Forward & $\begin{array}{l}\text { CGGCCTGCCAGCAGCAGAGCTAGGATAAG } \\
\end{array}$ & $74(28,48)$ & Hind III \\
\hline & & & Reverse & GTGCATTTTGTTTATCCATTCACaAG* & & \\
\hline \multirow[t]{2}{*}{ rs7366407 } & CASQ2 & $\mathrm{T}>\mathrm{A}$ & Forward & TTTTCTTGCTCCСATTCTGTTATTG & $130(58,72)$ & Mbo I \\
\hline & & & Reverse & AAAGGCTCTGGCTGTTGAATGGTAT & & \\
\hline \multirow[t]{2}{*}{ rs4292933 } & NOS1AP & $A>G$ & Forward & GAGCCTCA GTCCTGTAGC TGCCG & $93(26,67)$ & Nco I \\
\hline & & & Reverse & GGCTGTGTTCCTTTCTGAAGCcCA* & & \\
\hline \multirow[t]{2}{*}{ rs2824292 } & CXADR & $\mathrm{G}>\mathrm{A}$ & Forward & ССТССТАССТGСТGAAGCTGGAGACC & $94(24,70)$ & $A f a \mathrm{I}$ \\
\hline & & & Reverse & CTGTGCACCTGTTCCTTGCCTGgAT* & & \\
\hline
\end{tabular}

bp, base pairs; SNP, Single nucleotide polymorphism.

* Small letters show the mismatched bases used to artificially introduce endonuclease sites.

Table 2 General profiles in the case and control groups

\begin{tabular}{|c|c|c|c|c|c|c|}
\hline \multirow[t]{2}{*}{ Cause of death } & \multirow[t]{2}{*}{$\mathrm{N}$} & \multirow[t]{2}{*}{$\%$ Male } & \multicolumn{2}{|c|}{ Age (year) } & \multicolumn{2}{|c|}{ Heart weight (g) } \\
\hline & & & Mean (SD) & Range & Mean (SD) & Range \\
\hline Cardiomyopathy & 51 & $72.55 \%$ & $46.00(17.08)$ & $20-87$ & $471.17(168.04)$ & $229-900$ \\
\hline ARVC & 27 & $59.26 \%$ & $44.26(14.00)$ & $23-71$ & $369.70(96.44)$ & $229-567$ \\
\hline Non-ARVC & 24 & $87.50 \%$ & $42.62(20.29)$ & $19-80$ & $594.00(154.50)$ & $340-900$ \\
\hline Control & 172 & $68.02 \%$ & 46.97 (18.27) & $20-87$ & 351.31 (82.89) & $126-590$ \\
\hline Total & 223 & $69.06 \%$ & $48.16(15.51)$ & $19-87$ & $378.08(118.43)$ & $126-900$ \\
\hline
\end{tabular}

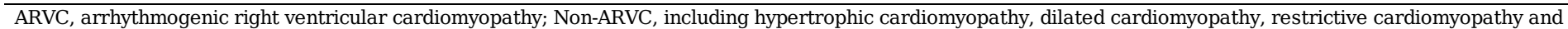
unclassified cardiomyopathy 
Table 3 Distribution of genotypic and allelic frequencies of four SNPs in cardiomyopathy cases and controls

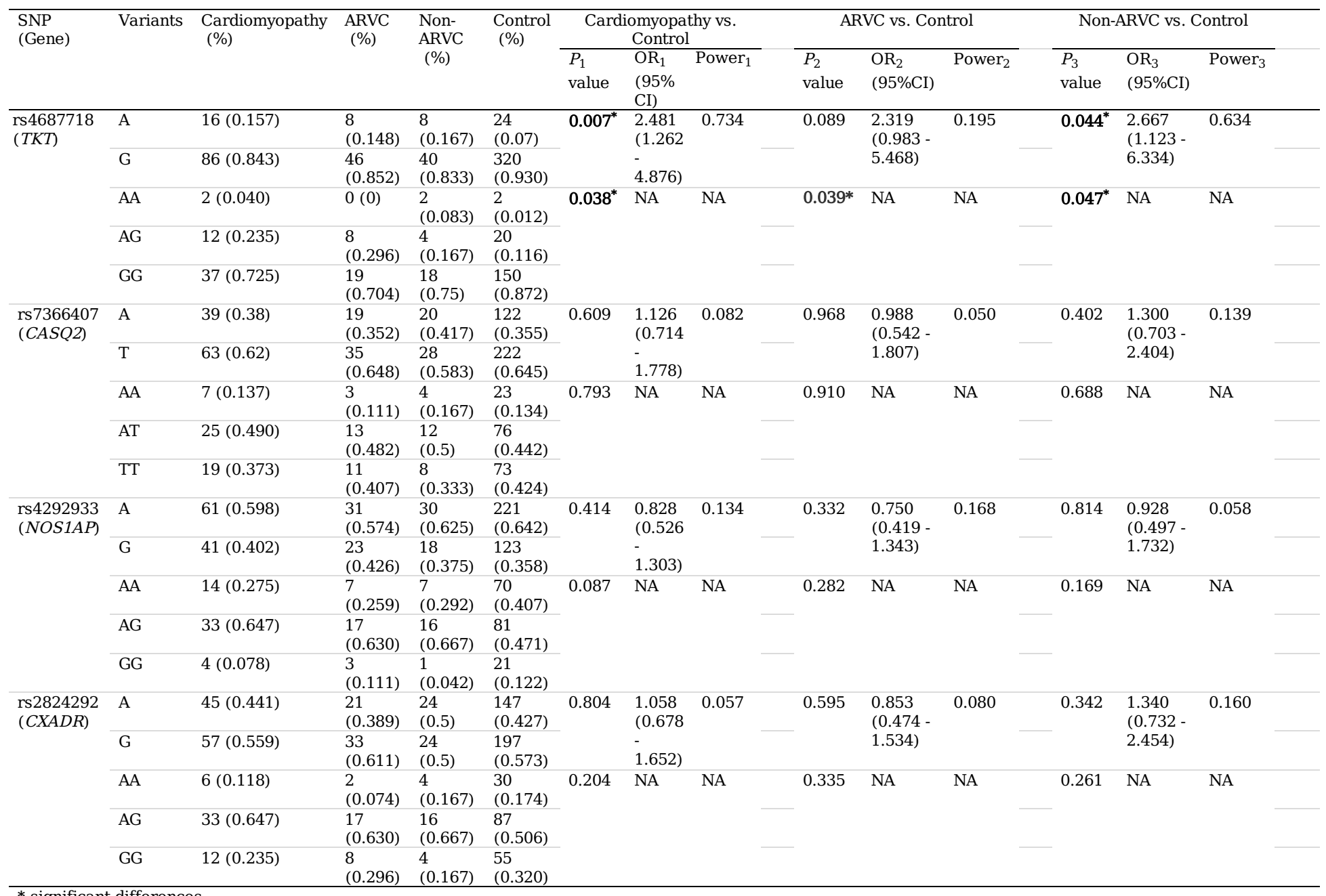

* significant differences

$P$ value, genotypic frequencies between cardiomyopathy cases and controls; OR, odds ratio; CI, confidence interval.

Table 4 Analysis of genotype distributions for rs4687718 between cardiomyopathy and control groups under four genetic models

\begin{tabular}{|c|c|c|c|c|c|c|c|c|c|c|c|c|}
\hline \multirow[t]{2}{*}{ Genetic model } & \multicolumn{3}{|c|}{ Cardiomyopathy vs. Control } & \multicolumn{3}{|c|}{ ARVC vs. Control } & \multicolumn{3}{|c|}{ Non-ARVC vs. Control } & \multicolumn{3}{|c|}{ ARVC vs. Non-ARVC } \\
\hline & $\begin{array}{l}P_{1} \\
\text { value }\end{array}$ & $\begin{array}{l}\mathrm{OR}_{1}(95 \% \\
\mathrm{CI})\end{array}$ & Power $_{1}$ & $\begin{array}{l}P_{2} \\
\text { value }\end{array}$ & $\begin{array}{l}\mathrm{OR}_{2} \\
(95 \% \mathrm{CI})\end{array}$ & Power $_{2}$ & $\begin{array}{l}P_{3} \\
\text { value }\end{array}$ & $\begin{array}{l}\mathrm{OR}_{3} \\
(95 \% \mathrm{CI})\end{array}$ & Power $_{3}$ & $\begin{array}{l}P_{4} \\
\text { value }\end{array}$ & $\begin{array}{l}\mathrm{OR}_{4} \\
(95 \% \mathrm{CI})\end{array}$ & Power $_{4}$ \\
\hline $\begin{array}{l}\text { Homozygous co- } \\
\text { dominant } \\
\text { (AA vs. GG) }\end{array}$ & 0.186 & $\begin{array}{l}4.054 \\
(0.553- \\
29.738)\end{array}$ & 0.374 & 0.615 & $\begin{array}{l}1.013 \\
(0.995- \\
1.032)\end{array}$ & 0.051 & 0.067 & $\begin{array}{l}8.333 \\
(1.105- \\
62.821)\end{array}$ & 0.428 & 0.487 & $\begin{array}{l}1.111 \\
(0.960- \\
1.286)\end{array}$ & 0.051 \\
\hline $\begin{array}{l}\text { Heterozygous co- } \\
\text { dominant } \\
\text { (AA vs. AG) }\end{array}$ & 0.634 & $\begin{array}{l}1.667 \\
(0.207- \\
13.428)\end{array}$ & 0.087 & 0.377 & $\begin{array}{l}1.100 \\
(0.964- \\
1.255)\end{array}$ & 0.055 & 0.191 & $\begin{array}{l}5.000 \\
(0.535- \\
46.719)\end{array}$ & 0.361 & 0.165 & $\begin{array}{l}1.500 \\
(0.852- \\
2.641)\end{array}$ & 0.062 \\
\hline $\begin{array}{l}\text { Recessive } \\
\text { (AA vs. AG+GG) }\end{array}$ & 0.225 & $\begin{array}{l}3.469 \\
(0.476- \\
25.268)\end{array}$ & 0.476 & 0.573 & $\begin{array}{l}1.012 \\
(0.995- \\
1.128)\end{array}$ & 0.059 & 0.074 & $\begin{array}{l}7.727 \\
(1.036- \\
57.651)\end{array}$ & 0.774 & 0.216 & $\begin{array}{l}1.091 \\
(0.967- \\
1.231)\end{array}$ & 0.051 \\
\hline $\begin{array}{l}\text { Dominant } \\
\text { (AA+AG vs. GG) }\end{array}$ & $0.012 *$ & $\begin{array}{l}2.580 \\
(1.206- \\
5.519)\end{array}$ & 0.914 & $0.047^{*}$ & $\begin{array}{l}2.871 \\
(1.122- \\
7.345)\end{array}$ & 0.853 & 0.197 & $\begin{array}{l}2.273 \\
(0.814- \\
6.344)\end{array}$ & 0.757 & 0.142 & $\begin{array}{l}2.667 \\
(0.707- \\
10.0520\end{array}$ & 0.641 \\
\hline
\end{tabular}

*significant

differences.

$P$ value, genotypic frequencies between cardiomyopathy cases and controls; OR, odds ratio; CI, confidence interval. 